\title{
Role of the overexpression of TRAF4 in predicting the prognosis of intrahepatic cholangiocarcinoma
}

\author{
QIANG KANG $^{1 *}$, HAO ZOU $^{1 *}$, LEI ZHOU $^{2 *}$, LI-XIN LIU ${ }^{1 *}$, JIA-BIN CAI $^{3}$, NAN XIE $^{1,3}$, \\ WEI-HAO LI ${ }^{4}$, CHAO ZHANG ${ }^{5}$, WAN-HONG SHI ${ }^{1}$, LIAN-MIN WANG ${ }^{1}$, \\ WEI-HAN ZHANG ${ }^{1}$, HONG ZHU ${ }^{1}$, SHU-FEN WANG ${ }^{2}$ and XIAO-WEN ZHANG ${ }^{1}$ \\ ${ }^{1}$ Department of Hepatobiliary Surgery, The Second Affiliated Hospital, Kunming Medical University, \\ Kunming, Yunnan 650106; ${ }^{2}$ Yunnan Key Laboratory of Stem Cells and Regenerative Medicine, \\ Institute of Molecular and Clinical Medicine, Kunming Medical University, Kunming, Yunnan 650031; \\ ${ }^{3}$ Liver Cancer Institute, Zhongshan Hospital, Fudan University, Shanghai 200032; \\ ${ }^{4}$ Department of Orthodontics, School and Hospital of Stomatology; ${ }^{5}$ School of Public Health, \\ Kunming Medical University, Kunming, Yunnan 650500, P.R. China
}

Received November 30, 2017; Accepted April 24, 2018

DOI: $10.3892 /$ ijo.2018.4383

\begin{abstract}
The incidence of intrahepatic cholangiocarcinoma (ICC) is progressively increasing worldwide, and its prognosis remains poor. Accumulating evidence has demonstrated that tumor necrosis factor receptor-associated factor 4 (TRAF4), an adaptor protein, is involved in the carcinogenesis and progression of several tumor types. However, the function of TRAF4 in predicting prognosis, and mediating
\end{abstract}

Correspondence to: Dr Xiao-Wen Zhang, Department of Hepatobiliary Surgery, The Second Affiliated Hospital, Kunming Medical University, 374 Dianmain Road, Wu Hua, Kunming, Yunnan 650106, P.R. China

E-mail: zhangxiaowenlu@163.com

Dr Shu-Fen Wang, Yunnan Key Laboratory of Stem Cells and Regenerative Medicine, Institute of Molecular and Clinical Medicine, Kunming Medical University, 1168 Chun Road West, Chenggong, Kunming, Yunnan 650031, P.R. China

E-mail:wsf66@hotmail.com

*Contributed equally

Abbreviations: TRAF4, tumor necrosis factor receptorassociated factor 4; ICC, intrahepatic cholangiocarcinoma; HCC, hepatocellular carcinoma; siRNA, small interfering RNA; EMT, epithelial-mesenchymal transition; TMA, tissue microarray; IHC, immunohistochemistry; RT-qPCR, reverse transcription-quantitative polymerase chain reaction; IF, immunofluorescence; GAPDH, glyceraldehyde 3-phosphate dehydrogenase; OS, overall survival; PI3K, phosphatidylinositol-3-kinase; TGF, transforming growth factor; NF- $\mathrm{BB}$, nuclear factor- $\kappa \mathrm{B}$; TNFR, tumor necrosis factor receptor

Key words: intrahepatic cholangiocarcinoma, tumor necrosis factor receptor-associated factor 4 , invasiveness, prognosis migration and invasion of ICC remains to be elucidated. In the present study, immunohistochemistry, western blotting and reverse transcription-quantitative polymerase chain reaction assays were used to determine that the expression of TRAF4 at the mRNA and protein levels in ICC tissues was significantly higher compared with that in non-tumor tissues. The overexpression of TRAF4 was positively correlated with poor differentiation, regional lymphatic metastasis, and high tumor-node-metastasis staging. Inhibiting the expression of TRAF4 using small interfering RNA decreased the migration and invasion of ICC cells in vitro. In addition, the AKT inhibitor perifosine eliminated the effect of TRAF4 on the invasion and migration of ICC cells in vitro. Clinically, the overexpression of TRAF4 was correlated with shorter overall survival rate and elevated recurrence rate in patients with ICC. Furthermore, patients with ICC with a high expression of TRAF4 and lymphatic metastasis were closely associated with a poorer prognosis compared with the other groups. Multivariate analysis indicated that the overexpression of TRAF4 was an independent prognostic indicator for patients with ICC. It was identified that a high level of TRAF4 facilitated the invasiveness of ICC cells via the activation of AKT signaling. The overexpression of TRAF4 may be a prognostic biomarker and candidate therapeutic target for patients with ICC.

\section{Introduction}

Intrahepatic cholangiocarcinoma (ICC) is the second most common primary malignant liver tumor following hepatocellular carcinoma (HCC) and accounts for $\sim 10 \%$ of all liver neoplasms $(1,2)$. The incidence and mortality rates of patients with ICC have gradually increased in the last several decades worldwide (2-4). Curative resection is the most effective treatment approach for patients with ICC, although the resection rate remains low due to local invasion and distant organ metastasis. Previous studies have indicated that ICC exhibits 
aggressive malignancy and has a higher malignancy than HCC $(5,6)$. The prognosis of patients with ICC remains poor, with a $30 \%$ 5-year overall survival (OS) rate, according to previous studies $(1,7,8)$. Therefore, more effective prognostic factors are required to improve the overall prognosis and to guide treatment approaches for patients with ICC.

The tumor necrosis factor receptor (TNFR)-associated factor (TRAF) family is comprised of TRAF1, 2, 3, 4, 5, 6 and 7 , and is part of the signal adaptor proteins in the cytoplasm (9). The TRAF proteins share a common structural organization in the C-terminal region, with the exception of TRAF7, in which this domain is replaced by seven WD40 repeats. In addition, TRAF proteins, with the exception of TRAF1, contain a RING domain in the N-terminal region that is involved in the ubiquitination pathway of protein degradation $(10,11)$. TRAFs can activate the p38, Janus kinase and nuclear factor (NF)- $\kappa \mathrm{B}$ signaling pathways by joining between the receptors of TNFR interleukin-1/Toll-like receptor family and signal cascades, and serve as regulators of these signaling pathways (9). Several studies have demonstrated that TRAFs are involved in a broad range of biological processes, including the metabolism of osteoblasts and osteoclasts, stress responses, embryonic development, and regulation of the normal immune system $(12,13)$. However, TRAF4, unlike other TRAF members, has not been found to be involved in immune progression and development, as no marked immunological defects or lymphocyte changes have been observed in TRAF4-deficient mice (14). Previous studies have revealed the importance of TRAF4 in embryogenesis and central nervous system myelin homeostasis $(15,16)$. During embryogenesis, the lack of expression of TRAF4 in TRAF4-deficient mice was shown to lead to embryonic developmental or life-threatening defects, including abnormal neural tube closure, axial skeleton malformations and tracheal abnormalities (17). The overexpression of TRAF4 has been verified in numerous types of cancer, including breast cancer, hepatocellular carcinoma, lung cancer and colon cancer (18-21). Several studies have reported that TRAT4 is crucial in a number of signaling pathways involved in tumorigenesis and progression, including phosphatidylinositol-3-kinase (PI3K)/AKT, transforming growth factor- $\beta$ (TGF- $\beta$ ), NF- $\kappa \mathrm{B}$ and Wnt- $\beta$-catenin (21-24). However, the role of TRAF4 in the progression of ICC remains to be elucidated. Therefore, examining whether TRAF4 is overexpressed in ICC, and whether it is correlated with the prognosis of ICC, were the objectives of the present study.

In the present study, the expression of TRAF4 was detected in ICC tissues with immunohistochemistry, and the associations between the expression of TRAF4 and the clinicopathological features of patients with ICC were determined. The effects of TRAF4 on the migration and invasion of the human RBE and HCCC9810 ICC cell lines were examined. Subsequently, whether the overexpression of TRAF4 was correlated with the Akt pathway was examined in vitro. Finally, the clinical prognostic implications of TRAF4 in patients with ICC were investigated.

\section{Materials and methods}

Patients and follow-up. A total of 98 paraffin-embedded ICC tumor and 22 non-tumor tissues were obtained from the
Second Affiliated Hospital of Kunming Medical University (Kunming, China; 85 with ICC and 22 with non-tumor tissues) and Shanghai Outdo Biotech Co., Ltd. (Shanghai, China; 13 with ICC), between January 2005 and December 2010 for immunohistochemical staining. The detailed clinicopathological features of the 98 patients with ICC recruited in the present study are listed in Table I. A total of 16 paired fresh tumor tissues and corresponding non-tumor tissues were collected for western blot and reverse transcription-quantitative polymerase chain reaction (RT-qPCR) analyses. Patients had not received preoperative antitumor treatment, including chemotherapy, radiotherapy, interventional therapy or anticancer drugs. The Child-Pugh scoring system was used to evaluate liver function (25). ICC histopathological diagnosis was conducted according to the World Health Organization criteria (26). Tumor differentiation was based on the Edmondson grading system (26). Tumor-node-metastasis (TNM) staging was based on the sixth edition of the TNM classification of the International Union Against Cancer (27). The present study was approved by the Medical Ethics Committee of the Second Affiliated Hospital of Kunming Medical University, and each patient signed an informed consent form. The exclusion criteria for patients with ICC were as follows: Presence of distant organ metastasis, possessing surgical contraindications, lymph node invasion exceeding hilar or hepatoduodenal ligament or the caval lymph nodes. The inclusion criteria for the patients with ICC were as follows: Age range 18-90 years old, first diagnosis of ICC, without other malignant tumors, confirmed R0 resection following surgery, uninterrupted clinical record, and whole pathological and histological data. The follow-up processes for the patients with ICC following surgery were as follows: Physical examination, epigastric ultrasonography and biochemical tests (used to monitor recurrence, when recurrence was suspected). Computed tomography or magnetic resonance imaging techniques were used to determine the presence of recurrence. The postoperative follow-up time was defined as follows: Every 2-6 weeks during the first 2 years, every 3-4 months between 2 and 5 years, and every 6 months thereafter. Patients with recurrence may be treated with minimally invasive therapy (radiofrequency ablation, arterial chemoembolization and percutaneous ethanol injection) or repeated hepatectomy based on the stage of tumor recurrence (size, number, site, lymph nodes and distant metastasis). The method of calculating the overall survival (OS) rate and the recurrence time was as described in an earlier study (28). The follow-up deadline was January 2017, and the median follow-up time of the 98 patients with ICC involved was 29.5 months (range, 4-120 months).

Tissue microarrays and immunohistochemistry. Tissue microarrays were constructed and immunohistochemistry was performed, as described in an earlier study $(28,29)$. A rabbit anti-human TRAF4 polyclonal antibody (cat. no. ab190986; 1:100; Abcam, Cambridge, UK) was used to detect the expression of TRAF4. The immunohistochemical staining of each section was assessed by two independent pathologists in a double-blinded manner. Images were analyzed using Image-Pro Plus 6.0 software (Media Cybernetics, Inc., Rockville, MD, USA). The standards for staining intensity were as follows: 0 , staining absent; 1 , weak brown; 2 , moderate 
Table I. Clinical characteristics of 98 patients with intrahepatic cholangiocarcinoma and expression of TRAF4.

\begin{tabular}{|c|c|c|c|}
\hline \multirow[b]{2}{*}{ Variable } & \multicolumn{3}{|c|}{ TRAF4 staining } \\
\hline & $\begin{array}{c}\text { High } \\
\text { expression }\end{array}$ & $\begin{array}{c}\text { Low } \\
\text { expression }\end{array}$ & P-value \\
\hline \multicolumn{4}{|l|}{ Age (years) } \\
\hline$\geq 53$ & 22 & 19 & 0.920 \\
\hline$<53$ & 30 & 27 & \\
\hline \multicolumn{4}{|l|}{ Sex } \\
\hline Male (30-79 years old) & 27 & 20 & 0.404 \\
\hline Female (31-81 years old) & 25 & 26 & \\
\hline \multicolumn{4}{|l|}{ CEA (ng/ml) } \\
\hline$\geq 5$ & 16 & 19 & 0.227 \\
\hline$<5$ & 36 & 27 & \\
\hline \multicolumn{4}{|l|}{ CA199 (ng/ml) } \\
\hline$\geq 37$ & 21 & 25 & 0.167 \\
\hline$<37$ & 31 & 21 & \\
\hline \multicolumn{4}{|l|}{ Tumor encapsulation } \\
\hline Absent & 13 & 15 & 0.405 \\
\hline Present & 39 & 31 & \\
\hline \multicolumn{4}{|l|}{ Maximal tumor diameter } \\
\hline$\geq 5 \mathrm{~cm}$ & 37 & 28 & 0.282 \\
\hline$<5 \mathrm{~cm}$ & 15 & 18 & \\
\hline \multicolumn{4}{|l|}{ Microvascular invasion } \\
\hline No & 10 & 10 & 0.758 \\
\hline Yes & 42 & 36 & \\
\hline \multicolumn{4}{|l|}{ Tumor number } \\
\hline Multiple & 9 & 4 & 0.210 \\
\hline Solitary & 43 & 42 & \\
\hline \multicolumn{4}{|l|}{ Tumor differentiation } \\
\hline III/IV & 37 & 18 & 0.001 \\
\hline $\mathrm{I} / \mathrm{II}$ & 15 & 28 & \\
\hline \multicolumn{4}{|l|}{ TNM stage } \\
\hline III/IV & 23 & 11 & 0.035 \\
\hline $\mathrm{I} / \mathrm{II}$ & 29 & 35 & \\
\hline \multicolumn{4}{|l|}{ Lymphatic metastasis } \\
\hline Yes & 17 & 6 & 0.022 \\
\hline No & 35 & 40 & \\
\hline
\end{tabular}

TRAF4, tumor necrosis factor receptor-associated factor 4; CEA, carcinoembryonic antigen; CA, carbohydrate antigen; TNM, tumornode-metastasis.

brown; 3, strong brown staining. The score for the mean area of staining was based on the percentage of positive staining cells that were judged as being moderately and strongly stained in tumor cells; ( $0,<5 \% ; 1,6-25 \% ; 2,26-50 \% ; 3,51-75 \% ; 4,>75 \%)$. The total scores were calculated by combining the staining intensity and the mean area. Patients with total scores of $<4$ were allocated to the low expression group (TRAF4 $4^{\text {low }}$ ), and those with scores of $\geq 4$ were placed in the high expression (TRAF4 ${ }^{\text {high }}$ ) group.
Cell lines and transfection. The RBE and HCCC9810 ICC cell lines were purchased from the Cell Bank of Chinese Academy of Sciences Shanghai Branch (Shanghai, China), and validated by short tandem repeat determination prior to the commencement of the study. The cells were cultured in RPMI-1640 medium (Gibco; Thermo Fisher Scientific, Inc., Waltham, MA, USA) supplemented with $10 \%$ heat-inactivated fetal bovine serum (FBS; Gibco; Fisher Scientific, Inc.) and incubated in a humidified atmosphere with $5 \% \mathrm{CO}_{2}$ at $37^{\circ} \mathrm{C}$. The AKT inhibitor perifosine (Beyotime Institute of Biotechnology, Shanghai, China) was used at a concentration of $45 \mu \mathrm{M}$ for $48 \mathrm{~h}$ to inhibit the activation of AKT in ICC cells. Small interfering (si)RNA transfection of the RBE and HCCC9810 cells was performed using Lipofectamine ${ }^{\circledR} 3000$ transfection reagent (Invitrogen; Thermo Fisher Scientific, Inc.) according to the manufacturer's protocols. The TRAF4 siRNA and control siRNA negative control (si-nc) were constructed by Shanghai Genomeditech Co, Ltd. (Shanghai, China). The siRNA sequences were as follows: siRNA-nc forward, 5'-UUC UCCGAACGUGUCACGUTT-3' and reverse, 5'-ACGUGACA CCGGAGAATT-3'; siRNA-TRAF4-1 forward, 5'-GCCCUAU CUUACAAUGGAUTT-3' and reverse, 5'-AUCCAUUGUAAG AUAGGGCTT-3'; and siRNA-TRAF4-2 forward, 5'-GUCUCU GGGUAUUGAAACUTT-3' and reverse, 5'-AGUUUCAAUA CCCAGAGACTT-3'. The mRNA and protein expression levels of TRAF4 were detected by RT-qPCR and western blot analyses, respectively.

$R N A$ extraction and $R T-q P C R$. Total RNAs were extracted from 16 cases of fresh ICC tissues and ICC cells using TRIzol reagent (Thermo Fisher Scientific, Inc.), according to the manufacturer's protocols. Total RNAs $(1 \mu \mathrm{g})$ were reverse transcribed into cDNA using the BeyoRT ${ }^{\mathrm{TM}}$ II cDNA synthesis kit (Beyotime Institute of Biotechnology) on the CFX96 ${ }^{\mathrm{TM}}$ Real-time system (Bio-Rad Laboratories, Inc. Hercules, CA, USA), with the temperature conditions as follows: $42^{\circ} \mathrm{C}$ for $60 \mathrm{~min}, 80^{\circ} \mathrm{C}$ for $12 \mathrm{~min}$. The qPCR analysis was then performed using Bestar $^{\circledR}$ Sybr Green qPCR master mix (DBI Bioscience, Shanghai, China) on the CFX96 Real-Time system (Bio-Rad Laboratories, Inc.). The quantity of sample components were as follows: cDNA $(2 \mu \mathrm{l})$; Bestar ${ }^{\circledR}$ Sybr Green qPCR master mix $(10 \mu \mathrm{l})$; forward primer $(0.6 \mu \mathrm{l})$; reverse primer $(0.6 \mu \mathrm{l})$; DEPC water $(6.8 \mu \mathrm{l}$; Beyotime Institute of Biotechnology). The thermocycling conditions for the RT-qPCR were as follows: Initial denaturation at $95^{\circ} \mathrm{C}$ for $5 \mathrm{~min}$; followed by 40 cycles of denaturation at $95^{\circ} \mathrm{C}$ for $10 \mathrm{sec}$; annealing at $53^{\circ} \mathrm{C}$ for $10 \mathrm{sec}$; and elongation at $73^{\circ} \mathrm{C}$ for $20 \mathrm{sec}$. The method of quantification was calculated with the $2^{-\Delta \Delta \mathrm{Cq}}$ method (30). All assays were repeated three times. Glyceraldehyde 3-phosphate dehydrogenase (GAPDH; B661104, Sangon Biotech Co., Ltd., Shanghai, China) was selected as an internal standard, the primer sequences for GAPDH were as follows: Forward, 5'-CAGGAGGCATTGCT GATGAT-3' and reverse, 5'-GAAGGCTGGGGCTCATTT-3'. The primers of TRAF4 (Sangon Biotech Co., Ltd.) were as follows: Forward, 5'-CTGGAAGATT GGCAGCTATGG-3' and reverse, 5'-GCCATTGAGGAATGCAGACA-3'.

Protein extraction and western blot analysis. A total of 16 cases of fresh ICC tissues and ICC cells were lysed in RIPA lysis 
buffer (Beijing Solarbio Science \& Technology Co., Ltd., Beijing, China). The total protein concentration was detected using the BCA (Beyotime Institute of Biotechnology) method. The proteins were then mixed with sample loading buffer (Beyotime Institute of Biotechnology), and denatured for $5 \mathrm{~min}$ at $100^{\circ} \mathrm{C}$ prior to the commencement of electrophoresis. The proteins $(80 \mu \mathrm{g})$ were separated via 10\% SDS-PAGE (Beijing Solarbio Science \& Technology Co., Ltd.) for $2 \mathrm{~h}$ at $80 \mathrm{~V}$ and then transferred onto polyvinylidene fluoride membranes (EMD Millipore, Billerica, MA, USA) for $90 \mathrm{~min}$ at $350 \mathrm{~mA}$. Following blocking with 5\% skimmed milk for $1 \mathrm{~h}$ at room temperature, the membranes were incubated with a rabbit anti-human TRAF4 polyclonal antibody (cat. no. ab190986; 1:1,000; Abcam), a mouse anti-human monoclonal Akt (pan) antibody (cat. no. 2920; 1:1,000; Cell Signaling Technology, Inc., Danvers, MA, USA), a rabbit anti-human phosphorylated (p)-Akt (Ser473) monoclonal antibody (cat. no. 4060, 1:1,000; Cell Signaling Technology, Inc.) and a mouse anti-human GAPDH monoclonal antibody (cat. no. AF0006; 1:1,000; Beyotime Institute of Biotechnology) overnight (beyond $16 \mathrm{~h}$ ) at $4^{\circ} \mathrm{C}$. Subsequently, the membranes were incubated with horseradish peroxidase (HRP)-labeled goat anti-rabbit (cat. no. A0208; 1:1,000; Beyotime Institute of Biotechnology) and anti-mouse (cat. no. A0216; 1:1,000; Beyotime Institute of Biotechnology) secondary antibodies for $60 \mathrm{~min}$ at room temperature. Finally, the membranes were visualized using a Novex ${ }^{\mathrm{TM}}$ ECL substrate reagent kit (Invitrogen; Thermo Fisher Scientific, Inc.) with the BioImaging system (Bio-Rad Laboratories, Inc.) and analyzed using Gel-Pro analyzer software (Media Cybernetics, Inc.). All assays were performed in triplicate.

Immunofluorescence (IF) and immunocytochemical staining. The IF staining was performed as described in an earlier study $(28,29)$, with minor modification. The ICC cells $\left(1 \times 10^{4}\right)$ were seeded into 24 -well plates on coverslips. After $24 \mathrm{~h}$, the coverslips were fixed in 95\% ethanol for 20 min, permeabilized for 15 min with $0.5 \%$ Triton X-100, had endogenous peroxidase depleted with $3 \%$ hydrogen peroxide for $20 \mathrm{~min}$, and were blocked for $30 \mathrm{~min}$ at room temperature in 5\% normal goat serum (Beyotime Institute of Biotechnology). The coverslips were incubated with primary antibodies [TRAF4: cat. no. ab190986; 1:50; Abcam; Akt (pan): cat. no. 2920; 1:50; Cell Signaling Technology, Inc.; p-Akt (Ser473): cat. no. 4060; 1:50; Cell Signaling Technology, Inc.] at $4^{\circ} \mathrm{C}$ overnight. Subsequently, the coverslips were incubated with FITC-labeled goat anti-mouse (cat. no. SF131; 1:30; Alexa 525; Beijing Solarbio Science \& Technology Co., Ltd.) and anti-rabbit (cat. no. SF134; 1:30; Alexa 525; Beijing Solarbio Science \& Technology Co., Ltd.) secondary antibodies at room temperature in the dark for $1 \mathrm{~h}$ and the nucleus counterstained for $5 \mathrm{~min}$ with DAPI (Beijing Solarbio Science $\&$ Technology Co., Ltd.). Images of the IF-stained coverslips were captured by confocal laser scanning microscopy (A1R; Nikon, Corporation, Tokyo, Japan). For the immunocytochemistry staining, the coverslips were incubated with HRP-labeled goat anti-rabbit and anti-mouse secondary antibodies (cat. no. K5007; undiluted; $100 \mu \mathrm{l} /$ cell sample; Dako, Glostrup, Denmark) at room temperature for 30 min, stained with DAB, and the nuclei counterstained with hematoxylin, prior to being mounted in neutral balsam. Images were captured using Leica Application Suite version 4.8.0 software (Leica Microsystems, Ltd., Milton Keynes, UK). The remaining procedures were consistent with the IF steps. All assays were performed in triplicate.

Invasion and migration assays. For the migration assay, 20,000 cells suspended in $200 \mu 1$ of serum-free RPMI-1640 medium were seeded into the top compartment $(8-\mu \mathrm{m}$ pore size; Corning Incorporated, Corning, NY, USA). Subsequently, $600 \mu \mathrm{l}$ of RPMI-1640 medium supplemented with 10\% FBS was added to the lower compartment. Following $48 \mathrm{~h}$ of incubation at $37^{\circ} \mathrm{C}$, the remaining cells on the upper side of the membrane were carefully removed using a cotton swab. The migrated cells on the lower side of the membrane were fixed with $4 \%$ paraformaldehyde (Beyotime Institute of Biotechnology) for $20 \mathrm{~min}$, stained with $0.1 \%$ crystal violet (Beijing Solarbio Science \& Technology Co., Ltd.) for $10 \mathrm{~min}$ and counted under a light microscope (IX83, Olympus Corporation, Tokyo, Japan). For the invasion assay, the upper Transwell chambers were pre-coated with Matrigel (BD Biosciences) and seeded with 40,000 cells. The subsequent procedures were as in the migration assay. All assays were repeated three times.

Wound-healing assays. The ICC cells were seeded into 24-well culture plates in RPMI-1640 medium containing 10\% FBS and grown to $90 \%$ confluence. A scratch wound was created using a 200- $\mu 1$ pipette tip. The cells were washed with PBS three times to remove cell debris, and then cultured in RPMI1640 medium containing low FBS $(0.5 \%)$ for $36 \mathrm{~h}$. Images were captured at 0 and $36 \mathrm{~h}$ with a phase-contrast microscope (IX83, Olympus Corporation). The cell migration areas were measured using Image-Pro Plus software version 6.0 (Media Cybernetics, Inc.). The wound-healing assays were performed in triplicate.

Statistical analysis. Statistical analyses were performed with SPSS software for windows version 21.0 (IBM, SPSS, Armonk, NY, USA). Data are presented as the mean \pm standard deviation. Differences between groups were compared using the $\chi^{2}$ test, Student's t-test, or one-way analysis of variance with the Least-Significant Difference correction. The OS and cumulative recurrence rates were assessed using the Kaplan-Meier method and the log-rank test. Cox's proportional hazards regression model was used to evaluate the independent prognostic factors. $\mathrm{P}<0.05$ was considered to indicate a statistically significant difference.

\section{Results}

TRAF4 is significantly upregulated in ICC tissues. To evaluate the expression of TRAF4 in patients with ICC, the expression of TRAF4 was examined in tumor tissues from 16 cases of ICC and corresponding non-tumor tissues by RT-qPCR and western blot analyses. The results demonstrated that the expression of TRAF4 in tumors was higher compared with that in corresponding non-tumor tissues at the mRNA (Fig. 1A, $0.357 \pm 0.106$, vs. $0.077 \pm 0.029, \mathrm{P}<0.001$ ) and protein (Fig. 1B, $1.151 \pm 0.572$, vs. $0.235 \pm 0.139, \mathrm{P}<0.001$ ) levels. The 

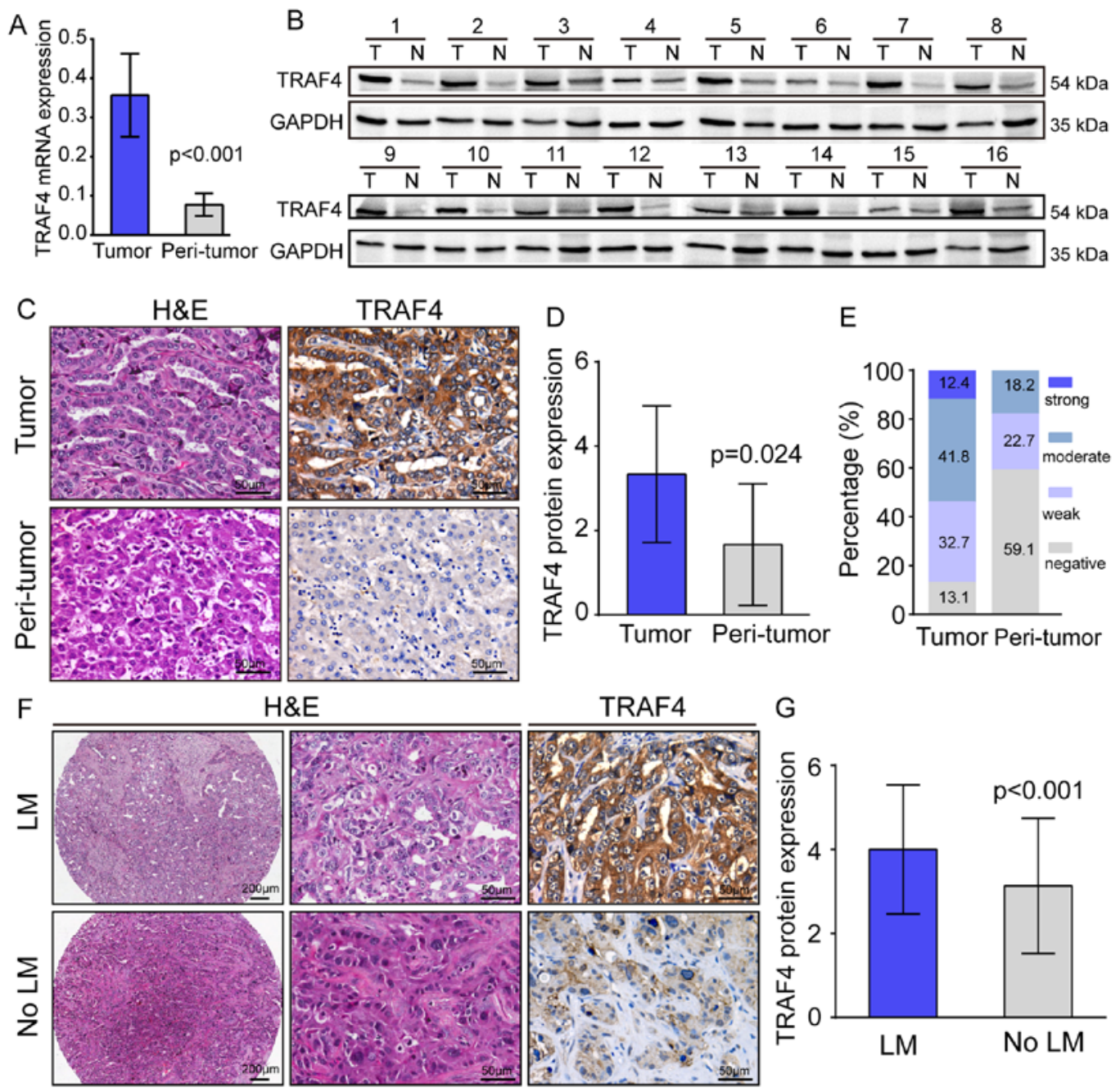

Figure 1. Expression of TRAF4 in tumor and non-tumor tissues of patients with ICC. (A) Reverse transcription-quantitative polymerase chain reaction and (B) western blot analyses of the expression of TRAF4 in 16 pairs of ICC tumor tissues and non-tumor tissues. (C) Representative images of H\&E and TRAF4 staining in ICC and non-tumor tissues. (D) Histogram showing that TRAF4 staining in ICC was more marked compared with non-tumor tissues (P<0.001). (E) Histogram of the percentages of differing staining intensity for TRAF4 in 98 patients with ICC. (F) Representative images of H\&E and TRAF4 staining in ICC and non-tumor tissues. (G) Histogram showing that the expression of TRAF4 in the tumor tissues of patients with ICC and lymphatic metastasis was higher compared with those without lymphatic metastasis. TRAF4, tumor necrosis factor receptor-associated factor 4; ICC, intrahepatic cholangiocarcinoma; T, tumor tissue; N, non-tumor tissue; H\&E, hematoxylin and eosin; LM, lymph node metastasis; GAPDH, glyceraldehyde 3-phosphate dehydrogenase.

expression of TRAF4 in 98 ICC tumor and 22 non-tumor tissues was further examined by IHC, and it was found that TRAF4 protein was mainly located in the cytoplasm of tumor cells (Fig. 1C), and that the protein level of TRAF4 in the tumor tissues was significantly higher compared with that in the non-tumor tissues (Fig. 1C and D). The overexpression of TRAF4 was observed in $53.1 \%$ (52/98) of the tumor tissue samples and $18.2 \%(4 / 22)$ of the non-tumor tissue samples (Fig. 1E). Furthermore, when the patients were divided into two groups based on the presence of lymphatic metastasis, the results revealed that patients with lymphatic metastasis had higher expression of TRAF4 (Fig. $1 \mathrm{~F}$ and G, 3.655 \pm 0.792 , vs. $2.360 \pm 0.509, \mathrm{P}=0.001)$.

Association between the expression of TRAF4 and the clinicopathological features of ICC. To assess the correlations between the level of TRAF4 and clinicopathological features, all patients with ICC were divided into high (TRAF4 ${ }^{\text {high }}$ ) and low (TRAF4 ${ }^{\text {low }}$ ) TRAF4 level groups according to the IHC staining. The results demonstrated that a high expression of TRAF4 was significantly correlated with malignant phenotype, including tumor differentiation $(\mathrm{P}=0.001)$, lymphatic metastasis $(\mathrm{P}=0.022)$ and TNM stage $(\mathrm{P}=0.035)$ (Table $\mathrm{I})$. However, no significant correlations were observed between other clinicopathological features, including sex, age, carcinoembryonic antigen, serum carbohydrate antigen 19-9, tumor encapsulation, microvascular invasion, tumor size and number, and the expression of TRAF4 (Table I).

TRAF4 regulates mobility and invasiveness in ICC via activating AKT signaling. Transient transfection of the RBE and HCCC9810 cells with downregulation of the expression of TRAF4 was verified by RT-qPCR (Fig. 2A) and western blot (Fig. 2B) analyses. Between the two candidate siRNAs, the transfection efficiency of siRNA-TRAF4-2 was higher compared with that of siRNA-TRAF4-1, and was selected for subsequent experiments. The Matrigel invasion and Transwell migration assays showed that the migration 

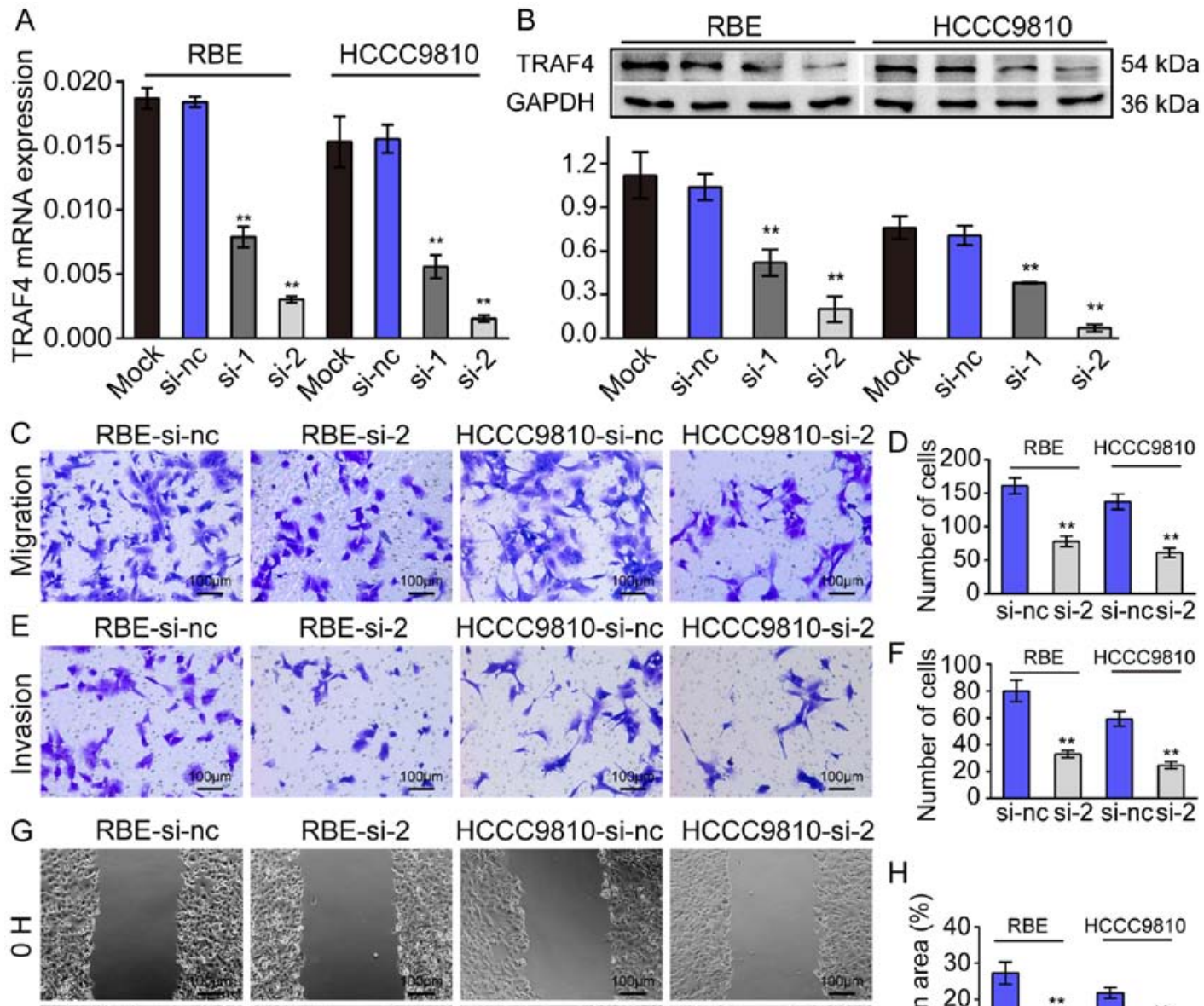

RBE-si-2
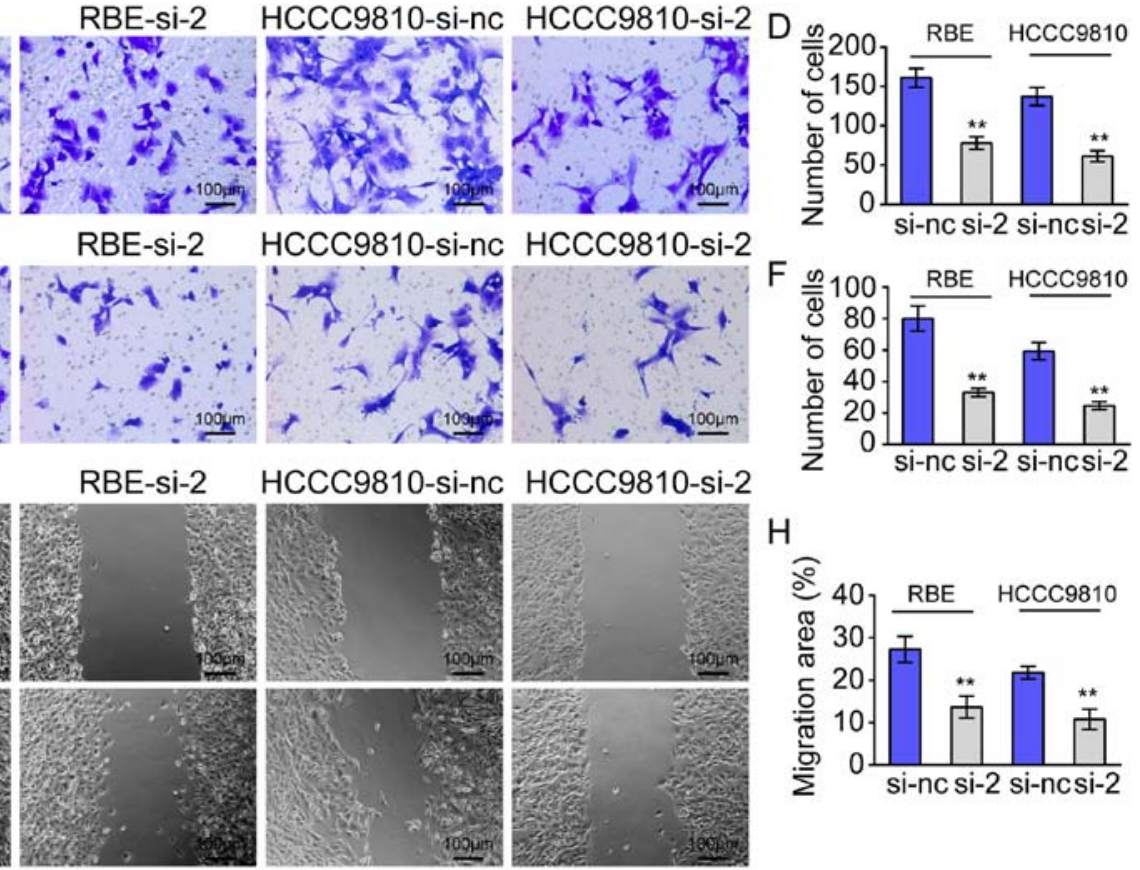

Figure 2. TRAF4 enhances ICC migration and invasion in vitro. (A) Reverse transcription-quantitative polymerase chain reaction and (B) western blot analyses demonstrated that the expression of TRAF4 in RBE and HCCC9810 cells were effectively inhibited. Transwell assays of the (C) staining and (D) quantification of cell migration, and (E) staining and (F) quantification of the invasion patterns of ICC cells with differing expression of TRAF4. (G) A wound-healing assay was used to measure the migratory abilities of ICC cells with differing expression patterns of TRAF4. (H) Migration areas. ${ }^{* *} \mathrm{P}<0.001$. TRAF4, tumor necrosis factor receptor-associated factor 4; GAPDH, glyceraldehyde 3-phosphate dehydrogenase; ICC, intrahepatic cholangiocarcinoma; si-, small interfering RNA; nc, negative control.

(Fig. 2C and D) and invasion (Fig. 2E and F) of ICC cells transfected with siRNA-TRAF4-2 were significantly inhibited compared with their corresponding controls. Similarly, the results of the wound-healing assays demonstrated that the downregulation of TRAF4 in ICC cells markedly reduced their migratory capacities (Fig. $2 \mathrm{G}$ and H). Furthermore, the level of AKT phosphorylation was downregulated in the ICC cells following TRAF4 interference (Fig. 3A-D). The ICC cells were treated with perifosine to inhibit the activation of AKT. The ICC cells with AKT inactivation showed weaker migration and invasion abilities compared with those in the ICC cell control (si-nc) groups (Fig. 4A-D). No significant differences were identified between the perifosine and si-TRAF4 groups (Fig. 4A-D).

Overexpression of TRAF4 is an independent marker for predicting prognosis in patients with ICC. The 2- and 5-year OS rates for the 98 patients with ICC were 77.5 and $25.6 \%$, respectively, and the cumulative recurrence rates were
63.3 and $79.1 \%$, respectively. The prognostic significance of the expression of TRAF4 in ICC patients was investigated. As shown in Fig. 5A, the expression of TRAF4 in ICC tumor tissues demonstrated considerable heterogeneity. The whole cohort was divided into TRAF4 ${ }^{\text {high }}$ and TRAF4 $4^{\text {low }}$ expression groups. The 2-year and 5-year OS rates in the TRAF4 $4^{\text {high }}$ group were markedly lower compared with those in the TRAF4 ${ }^{\text {low }}$ group (32.7, vs. $54.3 \%$ and 13.0 , vs. $34.6 \%$, respectively; Fig. 5B). The cumulative recurrence rates in the TRAF $4^{\text {high }}$ group were significantly higher compared with those in the TRAF4 $4^{\text {low }}$ group ( 77.0 vs. $50.3 \%$ and 86.2 vs. $66.1 \%$, respectively; Fig. 5C). Univariate analysis demonstrated that tumor differentiation, tumor number, TNM stage, lymphatic metastasis, and expression of TRAF4 were predictors for OS and cumulative recurrence rates. The multivariate Cox proportional hazards model demonstrated that the expression of TRAF4 was an independent prognostic factor for the OS and cumulative recurrence rates (Table II). In addition, it was found that patients with lymphatic metastasis and positive 

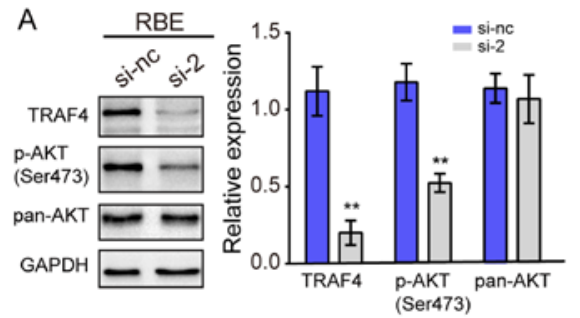

C
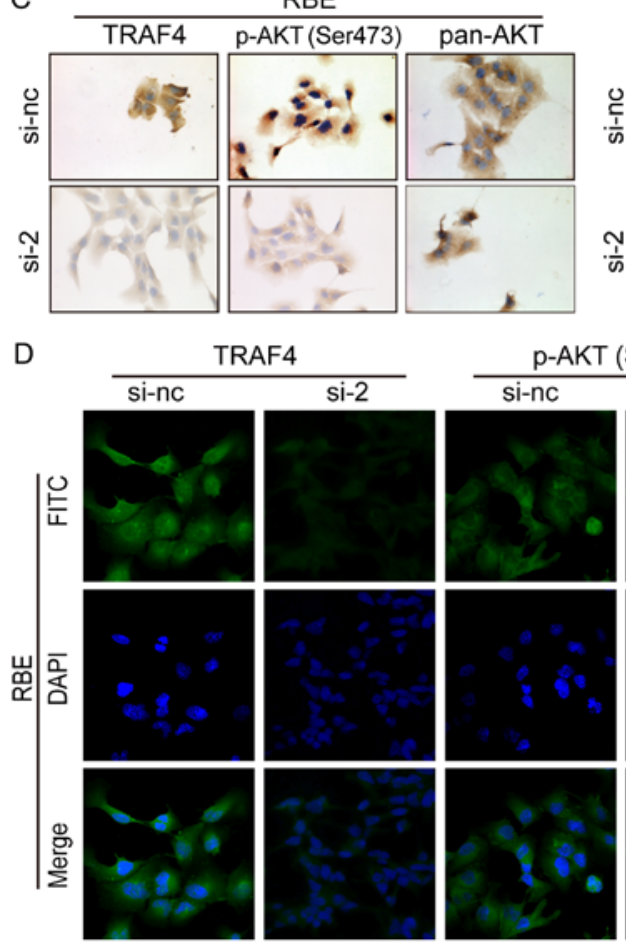
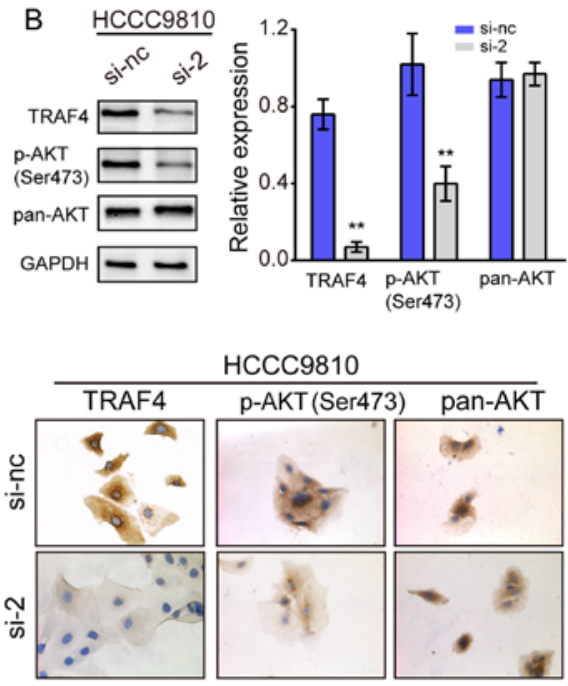

\section{si-2}
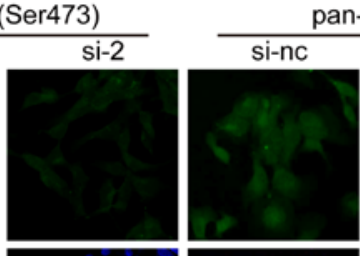

pan-AKT
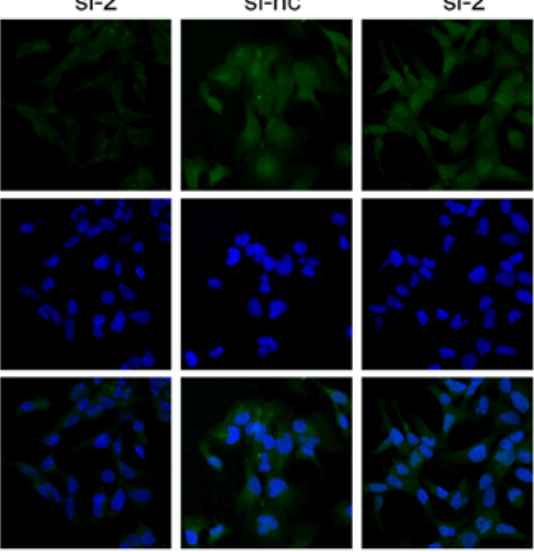

Figure 3. Downregulation of TRAF4 inhibits the phosphorylation of AKT of ICC cells in vitro. Western blot analysis indicated the downregulated expression of p-AKT (Ser473) in (A) RBE and (B) HCCC9810 cells with inhibited expression of TRAF4 $\left({ }^{* *} \mathrm{P}<0.001\right)$. Representative (C) immunocytochemical (magnification, $\mathrm{x} 200$ ) and (D) immunofluorescence images (magnification, x400) of TRAF4, p-AKT (Ser473) and pan-AKT in ICC cells with downregulated TRAF4 are shown. TRAF4, tumor necrosis factor receptor-associated factor 4; GAPDH, glyceraldehyde 3-phosphate dehydrogenase; p-AKT, phosphorylated AKT; ICC, intrahepatic cholangiocarcinoma; si-, small interfering RNA; nc, negative control.
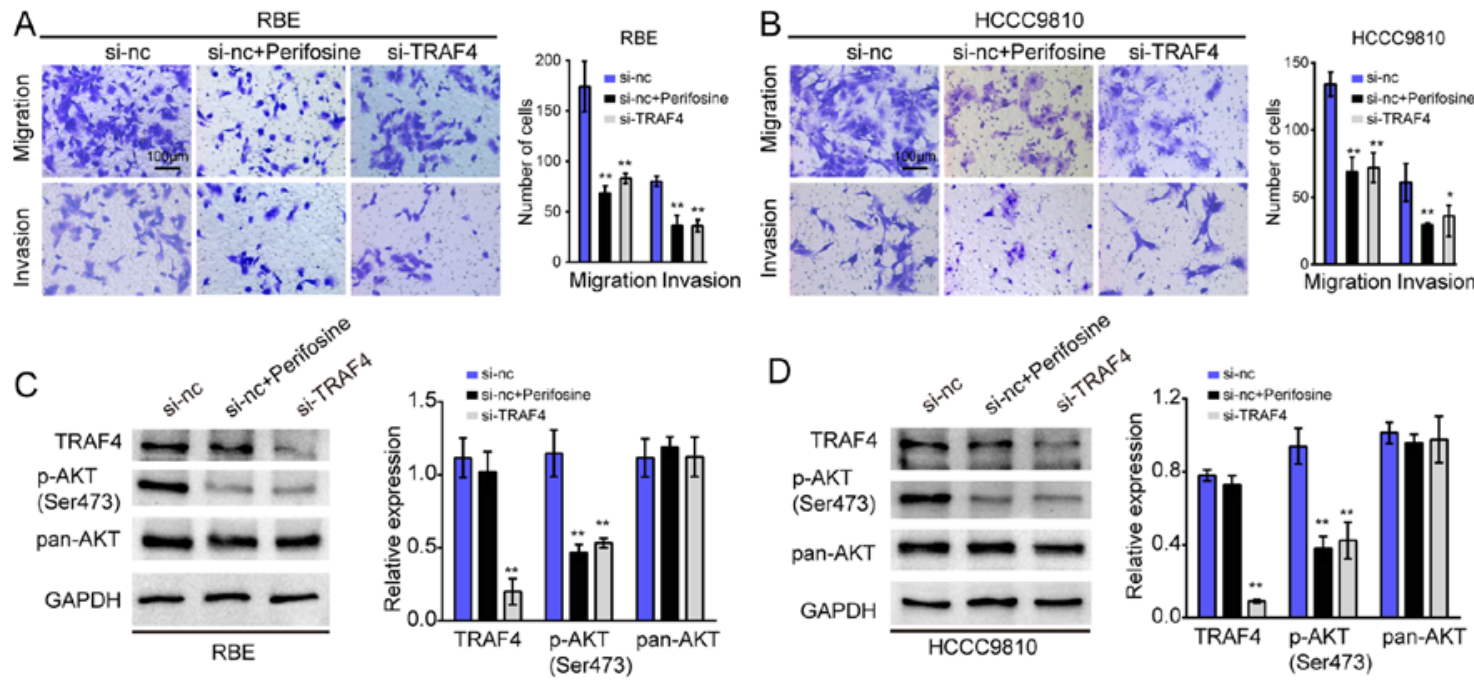

Figure 4. Effect of AKT inhibitor on the migration and invasion in ICC cells in vitro. Perifosine, the AKT inhibitor, markedly decreased (A) RBE cell migration and invasion, and (B) HCCC9810 cell migration and invasion, compared with the si-nc groups (magnification, $\mathrm{x} 100)$ ). ${ }^{*} \mathrm{P}<0.05,{ }^{* *} \mathrm{P}<0.001 \mathrm{vs}$. the si-nc group. No significant difference was observed between the perifosine and si-TRAF4 groups. The AKT inhibitor perifosine eliminated the TRAF4-induced activation of AKT in RBE (C) and HCCC9810 (D) cells. For TRAF4 protein expression, ${ }^{* *} \mathrm{P}<0.001$ vs. the si-nc + perifosine and si-nc groups; for p-AKT (Ser473) protein expression, ${ }^{* *} \mathrm{P}<0.001$ vs. the si-nc groups. TRAF4, tumor necrosis factor receptor-associated factor 4; GAPDH, glyceraldehyde 3-phosphate dehydrogenase; p-AKT, phosphorylated AKT; ICC, intrahepatic cholangiocarcinoma; si-, small interfering RNA; nc, negative control. 


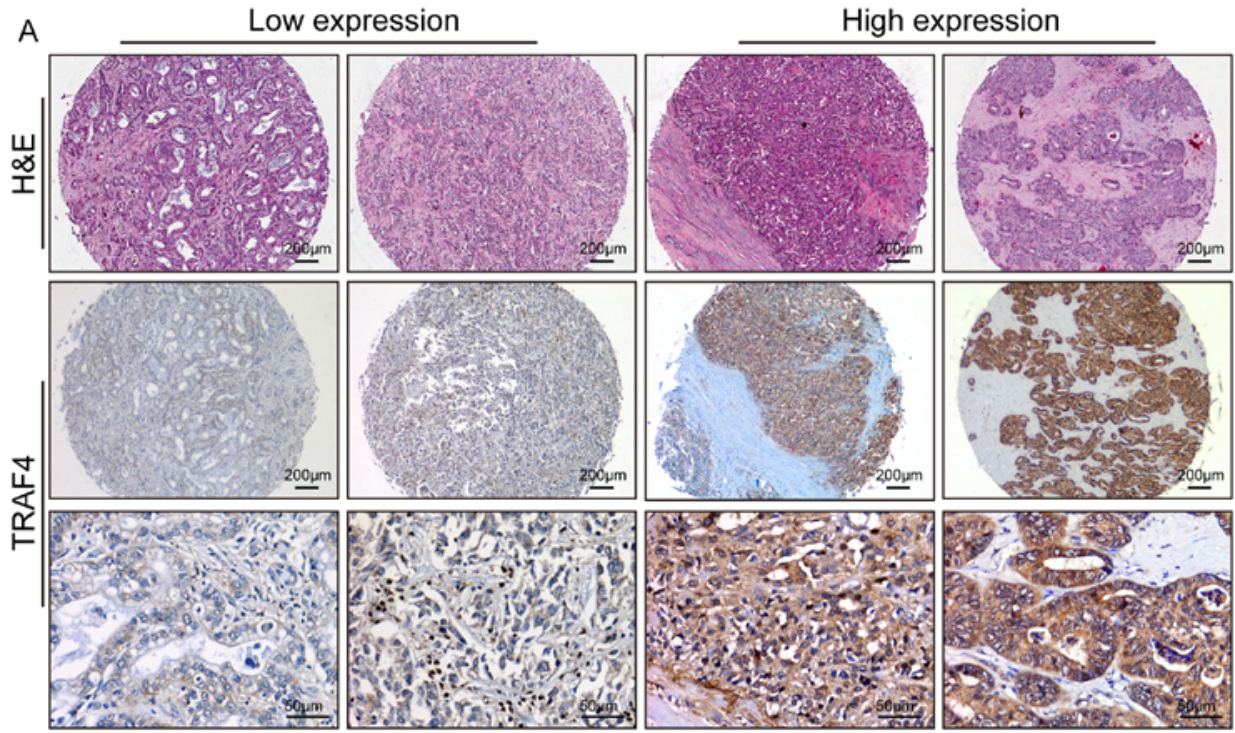

B
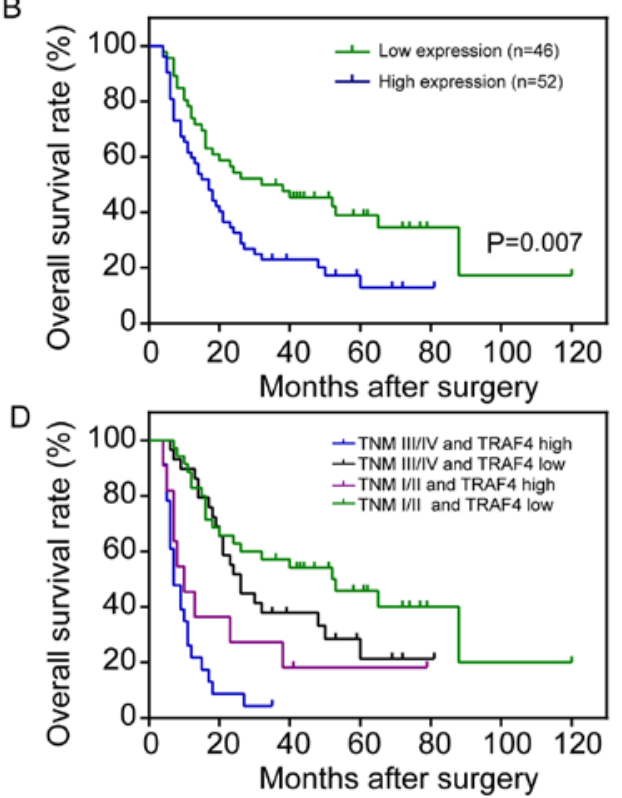
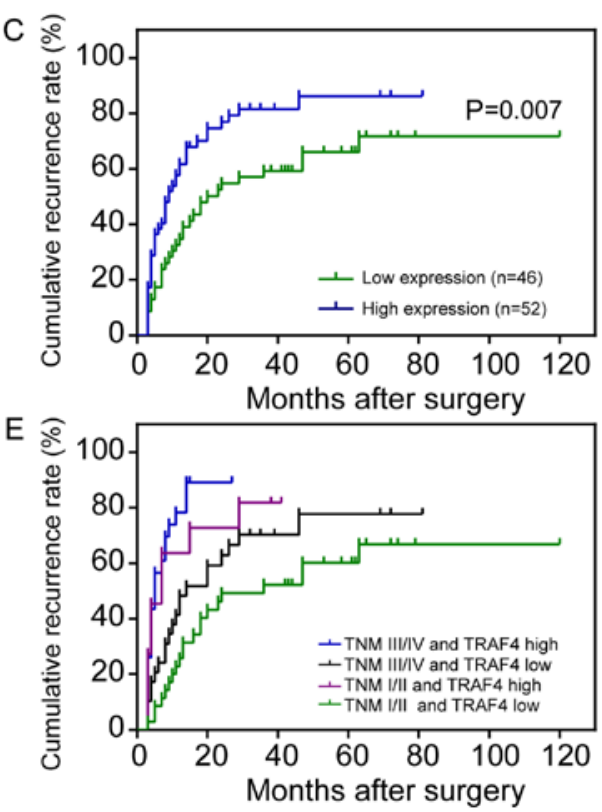

Figure 5. High levels of TRAF4 are significantly correlated with the poor prognosis of patients with ICC. (A) Representative immunohistochemical images of TRAF4 in ICC tissues. Patients with ICC and TRAF4 ${ }^{\text {high }}$ had (B) poorer OS and (C) higher cumulative recurrence rates. Patients with ICC, TRAF4 $4^{\text {high }}$ and lymphatic metastasis had (D) poorer OS and (E) higher cumulative recurrence rates in comparison with other subgroups. ICC, intrahepatic cholangiocarcinoma; TRAF4, tumor necrosis factor receptor-associated factor 4; TRAF4 ${ }^{\text {high }}$, high expression of TRAF4; H\&E, hematoxylin and eosin; OS, overall survival; TNM, tumor-node-metastasis.

TRAF4 staining had a significantly poorer OS rate and increased cumulative recurrence rate (Fig. 5D and E; both $\mathrm{P}<0.001)$.

\section{Discussion}

TRAF4 is one of the TRAF superfamily members. Functions of the TRAF4 protein are reportedly closely associated with developmental processes, producing reactive oxygen species, glucose metabolism, maintaining myelin homeostasis, autoimmune disease, cellular tight junctions, proliferation, polarity and metastasis. TRAF4 has been identified as overexpressed in several tumor types $(20,22,23)$. In the present study, it was consistently found that the expression of TRAF4 was markedly overexpressed at the protein and mRNA levels in ICC tissues compared with those in adjacent non-tumor tissues. Previous studies have demonstrated that TRAF4, a pivotal adapter in several signaling pathways which facilitates carcinogenesis and tumor progression, can bind to different downstream and upstream signaling proteins, and is also regulated by certain microRNAs $(20,31,32)$. In addition, Kim et al (33) demonstrated that inducing the expression of TRAF4 via irradiation in normal lung fibroblasts promoted the proliferation and epithelial-mesenchymal transition (EMT) of lung cancer cells via mediation of the tumor microenvironment. Clinically, the overexpression of TRAF4 is reported to be an important factor closely associated with vascular invasion, tumor numbers, maximum tumor size and histological type in patients with HCC and breast cancer $(21,34,35)$. These findings indicated a close association between TRAF4 
Table II. Univariate and multivariate analyses of factors associated with OS and cumulative recurrence rates in 98 patients with intrahepatic cholangiocarcinoma.

\begin{tabular}{|c|c|c|c|c|}
\hline \multirow[b]{2}{*}{ Factor } & \multicolumn{2}{|l|}{ OS rate } & \multicolumn{2}{|c|}{ Cumulative recurrence rate } \\
\hline & $\mathrm{HR}(95 \% \mathrm{CI})$ & P-value & $\mathrm{HR}(95 \% \mathrm{CI})$ & P-value \\
\hline \multicolumn{5}{|l|}{ Univariate analysis } \\
\hline Sex (male, vs. female) & $0.965(0.605-1.539)$ & 0.880 & $1.036(0.652-1.648)$ & 0.880 \\
\hline Age $(<53$, vs. $\geq 53$ years $)$ & $1.090(0.679-1.751)$ & 0.721 & $1.249(0.776-2.010)$ & 0.359 \\
\hline Serum CA19-9 (<37, vs. $\geq 37 \mathrm{ng} / \mathrm{ml})$ & $1.158(0.724-1.852)$ & 0.541 & $0.919(0.578-1.460)$ & 0.721 \\
\hline $\operatorname{CEA}(<5, \mathrm{vs} . \geq 5 \mathrm{ng} / \mathrm{m})$ & $1.091(0.672-1.770)$ & 0.725 & $1.435(0.872-2.361)$ & 0.155 \\
\hline Tumor encapsulation (absent, vs. present) & $1.386(0.802-2.394)$ & 0.242 & $0.845(0.632-1.752)$ & 0.845 \\
\hline Tumor differentiation (I/II, vs. III/IV) & $0.330(0.193-0.565)$ & $<0.001$ & $0.397(0.235-0.668)$ & 0.001 \\
\hline TNM stage (I/II, vs. III/IV) & $3.828(2.349-6.239)$ & $<0.001$ & $3.095(1.882-5.089)$ & $<0.001$ \\
\hline Maximal tumor size $(\leq 5$, vs. $>5 \mathrm{~cm})$ & $0.780(0.483-1.261)$ & 0.311 & $0.717(0.442-1.161)$ & 0.175 \\
\hline Microvascular invasion (no, vs. yes) & $1.169(0.660-2.071)$ & 0.592 & $1.061(0.591-1.904)$ & 0.843 \\
\hline Lymphatic metastasis (no, vs. yes) & $2.589(1.529-4.385)$ & $<0.001$ & $1.853(1.081-3.176)$ & 0.025 \\
\hline Tumor number (single, vs. multiple) & $2.604(1.417-4.786)$ & $<0.001$ & $2.726(1.463-5.077)$ & 0.002 \\
\hline TRAF4 staining (high, vs. low) & $1.910(1.181-3.090)$ & 0.008 & $1.870(1.162-3.011)$ & 0.010 \\
\hline \multicolumn{5}{|l|}{ Multivariate analysis } \\
\hline Tumor differentiation (I/II, vs. III/IV) & $0.302(0.172-0.530)$ & $<0.001$ & $0.389(0.225-0.671)$ & 0.001 \\
\hline TNM stage (I/II, vs. III/IV) & $5.919(2.722-12.871)$ & $<0.001$ & $4.721(2.219-10.045)$ & $<0.001$ \\
\hline Lymphatic metastasis (no, vs. yes) & $0.522(0.233-1.170)$ & 0.115 & $0.419(0.419-3.229)$ & 0.033 \\
\hline Tumor number (single, vs. multiple) & $1.671(0.847-3.297)$ & 0.139 & $1.605(0.798-3.229)$ & 0.185 \\
\hline TRAF4 staining (high, vs. low) & $1.941(1.133-3.324)$ & 0.016 & $1.833(1.085-3.096)$ & 0.023 \\
\hline
\end{tabular}

Statistical analysis was performed using Cox's proportional hazards regression model. CEA, carcinoembryonic antigen; CA, carbohydrate antigen; OS, overall survival; TNM, tumor-node-metastasis; TRAF4, tumor necrosis factor receptor-associated factor 4; CI, confidence interval; HR, hazard ratio.

and unfavorable prognoses in patients with breast cancer. Currently, it is generally accepted that TRAF4 serves as an oncogene. The present study further demonstrated that the overexpression of TRAF4 was significantly correlated with low differentiation, lymphatic metastasis and high TNM stage in patients with ICC. Notably, tumor tissues from patients with ICC who had lymphatic metastasis exhibited a higher expression level of TRAF4 compared with tissues from those without lymphatic metastasis. Notably, the results of the present study demonstrated that patients with ICC with TRAF $4^{\text {high }}$ had a poorer prognosis compared with those with TRAF4 ${ }^{\text {low }}$. The patients with ICC with TRAF4 ${ }^{\text {high }}$ and a high TNM stage had the poorest prognosis. These data provided sufficient clinical evidence that TRAF4 is involved in tumor progression and metastasis in patients with ICC, and that it may be a potential prognostic biomarker for ICC.

The results of the present study demonstrated that inhibition of the expression of TRAF4 using siRNA in RBE and HCCC 9810 cells impaired their motility and invasiveness of capabilities. Mechanistically, it was found that the downregulation of TRAF4 in ICC cells significantly inhibited the activation of AKT signaling in vitro, similarly consistent with previous studies $(21,24)$. Furthermore, the AKT inhibitor perifosine eradicated the effect of TRAF4 on the ICC cells. It was previously reported that the upregulation of TRAF4 increased the mobility and invasiveness of HCC cells in vivo and in vitro, and increased the level of the transcription factor slug, which acts as a key inducer of the EMT process, via activation of the PI3K/AKT signaling pathway (21). Yao et al (24) showed that TRAF4 fosters AKT membrane recruitment and, crucially, binds directly to AKT to promote the proliferation and invasion of breast cancer cells. In addition, TRAF4 directly interacts with TGF- $\beta$ protein, and enhances TGF- $\beta$-induced small mothers against decapentaplegic (SMAD) and non-SMAD signaling to drive breast cancer metastasis (22). The PI3K/Akt signaling pathway is known to belong to one of the important branches of non-SMAD pathways (36). These data indicate that TRAF4 is involved in tumor progression by directly and indirectly modulating the AKT signaling pathway. Taken together, the above data support the hypothesis that TRAF4 contributes to the progression of ICC through the activation of AKT signaling. However, there were several limitations in the present study. Firstly, the overexpression of TRAF4 in ICC cell lines is required for further verification of the role of TRAF4. Secondly, additional experiments in vivo are required to confirm these results.

In conclusion, the results of the present study demonstrated that the overexpression of TRAF4 enhanced the migration and invasion of ICC cells in vitro through the activation of AKT signaling, and that TRAF4 may serve as a novel prognostic indicator and potential molecular therapeutic target for patients with ICC. 


\section{Acknowledgements}

Not applicable.

\section{Funding}

This study was supported by the Scientific Research Foundation of Education Department of Yunnan Province (grant no. 2017YJS079), the National Natural Science Foundation of China (grant nos. 31460314 and 81760430), the Training Program Foundation of Medical Reserve Talent for Health and Family Planning Commission of Yunnan Province (grant no. H-201604) and Yunnan Applied Basic Research-Yunnan Provincial Science and Technology Department-Kunming Medical University joint key projects (grant no. 2015FA001)

\section{Availability of data and materials}

The datasets used and/or analyzed during the current study are available from the corresponding author on reasonable request.

\section{Authors' contributions}

$\mathrm{XWZ}, \mathrm{HaZ}$ and QK were involved in the conception and design of the study. QK, JBC and LZ wrote, reviewed and/or revised the manuscript. LZ also performed the cell experiments and interpreted the cell data. LXL, WHS and NX were involved in acquisition of data. QK, ZL and WHS conducted the immunohistochemical staining. WHZ, JBC and HaZ were involved in development of methodology and study design. QK, LXL, LMW and HoZ analyzed and interpreted the data. LZ, CZ and WHL provided administrative, technical or material support. $\mathrm{CZ}$ conducted reverse transcription-quantitative polymerase chain reaction. WHL was involved in fluorescent and immunocytochemical staining, and drafting the manuscript. XWZ and SFW supervised the study. SFW was also involved in critically revising the manuscript and conducting the cell experiments. All authors read and approved the final manuscript.

\section{Ethics approval and consent to participate}

The present study was approved by the Medical Ethics Committee of the Second Affiliated Hospital of Kunming Medical University, and each patient signed an informed consent form.

\section{Consent for publication}

Not applicable.

\section{Competing interests}

The authors declare that they have no competing interests.

\section{References}

1. Bagante F, Spolverato G, Weiss M, Alexandrescu S, Marques HP, Aldrighetti L, Maithel SK, Pulitano C, Bauer TW, Shen F, et al: Impact of morphological status on long-term outcome among patients undergoing liver surgery for intrahepatic cholangiocarcinoma. Ann Surg Oncol 24: 2491-2501, 2017.
2. Zhang H, Yang T, Wu M and Shen F: Intrahepatic cholangiocarcinoma: Epidemiology, risk factors, diagnosis and surgical management. Cancer Lett 379: 198-205, 2016.

3. Rahnemai-Azar AA, Weisbrod AB, Dillhoff M, Schmidt C and Pawlik TM: Intrahepatic cholangiocarcinoma: Current management and emerging therapies. Expert Rev Gastroenterol Hepatol 11: 439-449, 2017.

4. Yang LX, Gao Q, Shi JY, Wang ZC, Zhang Y, Gao PT, Wang XY, Shi YH, Ke AW, Shi GM, et al: Mitogen-activated protein kinase kinase kinase 4 deficiency in intrahepatic cholangiocarcinoma leads to invasive growth and epithelial-mesenchymal transition. Hepatology 62: 1804-1816, 2015.

5. Saha SK, Gordan JD, Kleinstiver BP, Vu P, Najem MS, Yeo JC Shi L, Kato Y, Levin RS, Webber JT, et al: Isocitrate dehydrogenase mutations confer dasatinib hypersensitivity and SRC dependence in intrahepatic cholangiocarcinoma. Cancer Discov 6: 727-739, 2016

6. Terashita K, Chuma M, Hatanaka Y, Hatanaka K, Mitsuhashi T, Yokoo $\mathrm{H}$, Ohmura T, Ishizu H, Muraoka S, Nagasaka A, et al: ZEB1 expression is associated with prognosis of intrahepatic cholangiocarcinoma. J Clin Pathol 69: 593-599, 2016.

7. Raoof M, Dumitra S, Ituarte PHG, Melstrom L, Warner SG, Fong Y and Singh G: Development and validation of a prognostic score for intrahepatic cholangiocarcinoma. JAMA Surg 152: e170117, 2017.

8. Zhu Z, Chen W, Yin X, Lai J, Wang Q, Liang L, Wang W, Wang A and Zheng C: WAVE3 induces EMT and promotes migration and invasion in intrahepatic cholangiocarcinoma. Dig Dis Sci 61: 1950-1960, 2016

9. Chung JY, Park YC, Ye H and Wu H: All TRAFs are not created equal: Common and distinct molecular mechanisms of TRAFmediated signal transduction. J Cell Sci 115: 679-688, 2002.

10. Xu LG, Li LY and Shu HB: TRAF7 potentiates MEKK3-induced AP1 and CHOP activation and induces apoptosis. J Biol Chem 279: 17278-17282, 2004.

11. Niu F, Ru H, Ding W, Ouyang S and Liu ZJ: Structural biology study of human TNF receptor associated factor 4 TRAF domain. Protein Cell 4: 687-694, 2013.

12. Wong BR, Josien R, Lee SY, Vologodskaia M, Steinman RM and Choi Y: The TRAF family of signal transducers mediates NF-kappaB activation by the TRANCE receptor. J Biol Chem 273: 28355-28359, 1998.

13. Xie P: TRAF molecules in cell signaling and in human diseases. J Mol Signal 8: 7, 2013.

14. Cherfils-Vicini J, Vingert B, Varin A, Tartour E, Fridman WH, Sautès-Fridman C, Régnier $\mathrm{CH}$ and Cremer I: Characterization of immune functions in TRAF4-deficient mice. Immunology 124: 562-574, 2008

15. Blaise S, Kneib M, Rousseau A, Gambino F, Chenard MP, Messadeq N, Muckenstrum M, Alpy F, Tomasetto C, Humeau Y, et al: In vivo evidence that TRAF4 is required for central nervous system myelin homeostasis. PLoS One 7: e30917, 2012.

16. Masson R, Régnier CH, Chenard MP, Wendling C, Mattei MG, Tomasetto $\mathrm{C}$ and Rio MC: Tumor necrosis factor receptor associated factor 4 (TRAF4) expression pattern during mouse development. Mech Dev 71: 187-191, 1998.

17. Régnier CH, Masson R, Kedinger V, Textoris J, Stoll I, Chenard MP, Dierich A, Tomasetto $\mathrm{C}$ and Rio MC: Impaired neural tube closure, axial skeleton malformations, and tracheal ring disruption in TRAF4-deficient mice. Proc Natl Acad Sci USA 99: 5585-5590, 2002.

18. Tomasetto C, Régnier C, Moog-Lutz C, Mattei MG, Chenard MP, Lidereau R, Basset P and Rio MC: Identification of four novel human genes amplified and overexpressed in breast carcinoma and localized to the q11-q21.3 region of chromosome 17. Genomics 28: 367-376, 1995.

19. Li W, Peng C, Lee MH, Lim D, Zhu F, Fu Y, Yang G, Sheng Y, Xiao L, Dong X, et al: TRAF4 is a critical molecule for Akt activation in lung cancer. Cancer Res 73: 6938-6950, 2013.

20. Yang K, Wang F and Han JJ: TRAF4 promotes the growth and invasion of colon cancer through the Wnt/ $\beta$-catenin pathway. Int J Clin Exp Pathol 8: 1419-1426, 2015.

21. Liu K, Wu X, Zang X, Huang Z, Lin Z, Tan W, Wu X, Hu W, Li B and Zhang L: TRAF4 regulates migration, invasion, and epithelial-mesenchymal transition via PI3K/AKT signaling in hepatocellular carcinoma. Oncol Res 25: 1329-1340, 2017.

22. Zhang L, Zhou F, García de Vinuesa A, de Kruijf EM, Mesker WE, Hui L, Drabsch Y, Li Y, Bauer A, Rousseau A, et al: TRAF4 promotes TGF- $\beta$ receptor signaling and drives breast cancer metastasis. Mol Cell 51: 559-572, 2013. 
23. Yang J, Wei D, Wang W, Shen B, Xu S and Cao Y: TRAF4 enhances oral squamous cell carcinoma cell growth, invasion and migration by Wnt- $\beta$-catenin signaling pathway. Int J Clin Exp Pathol 8: 11837-11846, 2015.

24. Yao W, Wang X, Cai Q, Gao S, Wang J and Zhang P: TRAF4 enhances osteosarcoma cell proliferation and invasion by Akt signaling pathway. Oncol Res 22: 21-28, 2014.

25. Talwalkar JA, Seaberg E, Kim WR and Wiesner RH; National Institutes of Diabetes and Digestive and Kidney Diseases Liver Transplantation Database Group: Predicting clinical and economic outcomes after liver transplantation using the Mayo primary sclerosing cholangitis model and Child-Pugh score. Liver Transpl 6: 753-758, 2000.

26. Wittekind C: Pitfalls in the classification of liver tumors. Pathologe 27: 289-293, 2006 (In German).

27. Lei HJ, Chau GY, Lui WY, Tsay SH, King KL, Loong CC and Wu CW: Prognostic value and clinical relevance of the 6th Edition 2002 American Joint Committee on Cancer staging system in patients with resectable hepatocellular carcinoma. J Am Coll Surg 203: 426-435, 2006.

28. Kang Q, Cai JB, Dong RZ, Liu LX, Zhang C, Zhang PF, Zou H, Xie N, Zhang L, Zhang XY, et al: Mortalin promotes cell proliferation and epithelial mesenchymal transition of intrahepatic cholangiocarcinoma cells in vitro. J Clin Pathol 70: 677-683, 2017.

29. Zou H, Liu Y, Wei D, Wang T, Wang K, Huang S, Liu L, Li Y, Ge J, Li X, et al: Leptin promotes proliferation and metastasis of human gallbladder cancer through OB-Rb leptin receptor. Int J Oncol 49: 197-206, 2016.
30. Livak KJ and Schmittgen TD: Analysis of relative gene expression data using real-time quantitative PCR and the $2(-\Delta \Delta \mathrm{C}(\mathrm{T}))$ Method. Methods 25: 402-408, 2001.

31. Chen T, Gao F, Feng S, Yang T and Chen M: MicroRNA-370 inhibits the progression of non-small cell lung cancer by downregulating oncogene TRAF4. Oncol Rep 34: 461-468, 2015.

32. Lu TY, MacDonald JM, Neukomm LJ, Sheehan AE, Bradshaw R, Logan MA and Freeman MR: Axon degeneration induces glial responses through Draper-TRAF4-JNK signalling. Nat Commun 8: 14355, 2017.

33. Kim E, Kim W, Lee S, Chun J, Kang J, Park G, Han I, Yang HJ, Youn $\mathrm{H}$ and Youn B: TRAF4 promotes lung cancer aggressiveness by modulating tumor microenvironment in normal fibroblasts. Sci Rep 7: 8923, 2017.

34. Yang F, Wang J, Ren HY, Jin J, Wang AL, Sun LL, Diao KX, Wang EH and Mi XY: Proliferative role of TRAF4 in breast cancer by upregulating PRMT5 nuclear expression. Tumour Biol 36: 5901-5911, 2015

35. Ren HY, Wang J, Yang F, Zhang XL, Wang AL, Sun LL, Diao KX, Wang EH and Mi XY: Cytoplasmic TRAF4 contributes to the activation of p70s6k signaling pathway in breast cancer. Oncotarget 6: 4080-4096, 2015.

36. Zhang YE: Non-Smad pathways in TGF-beta signaling. Cell Res 19: 128-139, 2009. 